\title{
Thirty years on from Alma-Ata: Where have we come from? Where are we going?
}

Trisha Greenhalgh

The 2008 William Pickles Lecture coincided with a number of important anniversaries: 60 years since Pickles published his landmark monograph 'Epidemiology in Country Practice';' 40 years since Pat Byrne gave the first William Pickles Lecture at the Royal College of General Practitioners; and 30 years since the publication of the Alma-Ata Declaration. ${ }^{2}$

In my lecture, I cover four themes. First, whatever happened to what is sometimes depicted as the idyllic life of the William Pickles-style country GP? Second, whatever happened to Alma-Ata? Third, what - more generally - do these changes represent? And finally, what (if anything) can we salvage from our nostalgic memories of oldfashioned general practice that will help us in our contemporary role as primary care practitioners?

William Pickles was a GP in the glorious setting of Wensleydale in the Yorkshire Dales from 1922 until the mid 1960s. He demonstrated that high-quality epidemiological research can be achieved if family doctors think hard about their practice, pursue their clinical and scientific hunches, and keep meticulous records. ${ }^{1}$ His intimate knowledge of the local rural community and its ways; his simple hand-drawn epidemiological charts; and his ruthless hunting down of the social contacts of people with contagious diseases, equipped him to make significant contributions to the science of epidemiology including documenting the incubation period of measles, influenza, hepatitis A, and dysentery, as well as helping to establish the link between chickenpox and shingles.

Wensleydale in the early 20th century was a quintessentially English farming community. It was by no means affluent but it was close-knit, hard-working, and focused almost exclusively on the core business of growing crops, tending livestock, and getting products to market. Records suggest that the family doctor was a unique and respected member of such rural communities, who tended to suffer high levels of illness with a predominance of acute, infectious conditions. The social structure of the community was such that home visits were common, and the GP's Gladstone bag and big black overcoat were as essential as his stethoscope. With few effective remedies available, this was the era when, to use Michael Balint's powerful metaphor, the doctor was the drug. ${ }^{3}$

Much has changed. Following a period of relative affluence after the Second World War, the Wensleydale of 2008 has gone the way of many other traditional farming communities across Europe: squeezed into recession by the forces of global competition and the unequal impact of the Common Agricultural Policy. The once-isolated farming community has had to adapt to survive. It now milks the benefits of set-aside legislation drawn up in Brussels, which has allowed new industries to emerge: tourism (such as the Wallace and Gromit cheese factory), film (Wensleydale is the setting for the rustic scenes of 'All Creatures Great and Small'), care homes (many farmers have sold up to the developers of residential and nursing homes), and food and drink (especially the scenic country pub serving real ale). Pickles' successors in rural Yorkshire battle with the contemporary pandemics of obesity, diabetes, and chronic depression in an increasingly sedentary and socially fragmented population, and with a younger generation who relish the risk-taking of alcohol abuse and dangerous driving.

My second theme is Alma-Ata. The name 'AlmaAta' means 'rich with apple', and today this city is a part of Kazakhstan. But back in 1978, it was a provincial city in Brezhnev's USSR. Like all Soviet cities of the time, Alma-Ata was a place of food queues and inefficient, nationalised industries, in

T Greenhalgh, OBE, MD, FRCGP, FRCP, FHEA, professor of primary health care, University College London, London. This text is based on the William Pickles Lecture delivered at the Royal Geographical Society, London on the 16 May 2008.

Address for correspondence

Trisha Greenhalgh, University College London, 206 Holborn

Union Building, Highgate Hill, London N19 5LW.

E-mail: p.greenhalgh@pcps.ucl.ac.uk

Submitted: 19 May 2008; Editor's response: 3 July 2008; final acceptance: 22 July 2008.

@British Journal of General Practice 2008; 58: 798-804.

DOI: 10.3399/bjgp08X342679 
which traditional architecture like Alma-Ata's Russian Orthodox cathedral stood alongside soulless blocks of workers' flats. The countryside around Alma-Ata was famous for getting rained with debris that fell off rockets in the Russian space programme. Few of us would have heard of it had an enlightened group of planners not sought to supplement their meagre economy with a bit of conference income. The city was perhaps an inauspicious setting for the drafting of the first official international declaration on the importance of primary health care.

The Declaration - or 'Alma-Ata' as it is universally known - placed health in the foremost of all human rights. $^{2}$ It made bold claims for the link between health and socioeconomic inequalities (and was published, notably, months before the Thatcher government in the UK pulped all but 260 copies of the Black Report on Inequalities in Health). ${ }^{4}$ Alma-Ata celebrated, and sought to enhance, the role of the patient in managing his or her own care - and also the role of communities in planning and evaluating services. It recognised that effective primary health care needs an evidence base, and called for research funding to explore the burden, causes, and management of illness. It highlighted the close relationship between primary health care, public health, community development, patient education, housing, and people's diet and lifestyles. And it predicted that although there is an urgent need to build capacity in primary health care, politicians and policymakers would not necessarily see it that way.

What has happened to the city of Alma-Ata since 1978 ? It certainly went through a rough patch in the mid 1990s. The Royal Free Medical School sent Julian and Mary Tudor Hart there in 1995, and I am grateful to the former for sending me the report he wrote on the state of health and health services there. He described $1000 \%$ inflation, abject poverty not just in the population but in the doctors and nurses who served them, and the early signs of frank malnutrition in children. ${ }^{5}$

But this was temporary. Soon afterwards, AlmaAta reinvented itself. It is now known as Almaty, and resides in the Independent Republic of Kazakhstan, famously misrepresented in the film 'Borat' as economically and culturally underdeveloped. In reality, Kazakhstan is doing better than Wensleydale in economic terms, with Gross Domestic Product growing at an average rate of 10 per cent per year since $2001 .{ }^{6}$ The upturn in its fortunes can be traced back to what is termed 'multidimensional foreign policy' - that is, being nice to both Russia to the north and China to the east - and also to the Caspian Pipeline Consortium - a massive, high-risk partnership set up in 1998 between various Soviet states and the US company Chevron to build an export route for oil from the landlocked countries of the former USSR. ${ }^{6}$ Kazakhstan's oil reserves have increased ten-fold in the last 5 years and are now valued at tens of billions of dollars. ${ }^{6}$ With the money, Almaty has built an impressive skyline of skyscrapers, hosted the International Fashion Week, and put in a bid to host the 2022 Winter Olympics.

Healthcare needs have changed too. Almaty's citizens have taken to spending their rising disposable income on the vices of modern society. McDonaldisation came to Kazakhstan in the late 1990s, and the obesity epidemic followed soon after. ${ }^{7,8}$ Around $62 \%$ of men are regular smokers, and that rises to over $70 \%$ in the under $40 \mathrm{~s} .{ }^{9}$ Alcohol intakes, while traditionally high, have risen sharply since oil money started pouring in, ${ }^{10}$ as have rates of drug abuse: of a population of 15 million, there are 50000 registered addicts and an estimated 250000 using illegal drugs regularly. ${ }^{7,11}$ Sexually transmitted infections and unwanted pregnancy are common. While contraception is now fairly widely available, a strong abortion legacy from the Soviet years remains, and thousands of young women have abortions annually. ${ }^{12}$ The Kazakhstan Department of Health recently identified domestic violence as one of the country's top health priorities. It is, apparently, both widespread and deep-rooted, and stems from women beginning to question their traditional role and resist domestic and sexual coercion - while most men remain united in agreement that this is unreasonable and against the principles of Islam. ${ }^{13}$

Thus, the traditional Soviet city of Alma-Ata has, like Wensleydale, adapted to survive. In the last 30 years it has seen rapid political and economic change: liberation from communism; international investment in infrastructure; and efficient tapping of its natural resources via large-scale partnerships with industry. In 10 years, the burden of health need has shifted from a 'third-world' pattern to a typical 'transition country' pattern, with high levels of smoking-, alcohol- and drug-related diseases as well as accidents and violence, attributed at least partly to 'culture clashes' between traditional and modern values.

The third theme of my lecture is what, more generally, do these changes represent? I think they reflect four important social trends in our society: globalisation, modernisation, individualisation, and consumerism. Let's take them one by one.

In the words of Professor Anthony Giddens, who covered globalisation in his 1999 Reith Lectures:

'We live in a world of transformations, affecting almost every aspect of what we do. For better or worse, we are being propelled into a global order that no one fully understands, but which is making its effects felt upon all of us. ${ }^{14}$ 
Giddens argued that there are two different takes on globalisation. The first is the conventional take: that it is essentially a unidimensional, economic phenomenon characterised by the expansion of international trade, by unprecedented amounts of money moving around the world (the so-called electronic dollar, pound, and yen) with the potential to destabilise national economies. This take on globalisation has it as a unidirectional phenomenon, pulling power away from local communities and into the global economy, where small numbers of people make obscene profits. It is a phenomenon that is considered to be 'out there' and 'big picture', in which national sovereignty is subverted to macro-economic influences. In the words of business tycoon Keniche Ohmae, cited by Giddens in his lecture, 'nations have become mere fictions'. ${ }^{14}$ The ability of individual African governments to set and implement policy on HIV and malaria, for example, is no longer independent of how Bill Gates chooses to spend his small change. More worryingly, the ability of China to control the devastating health impact of smoking is no longer independent of how companies like British American Tobacco choose to spend theirs.

But there is a more radical take on globalisation, which has it as a multidimensional phenomenon. The movement of people, knowledge, and ideas around the globe is as important as the movement of money. 'Web 2.0' - defined by Wikipedia as 'the trend in the use of World Wide Web technology and web design that aims to enhance creativity, information sharing, and, most notably, collaboration among users' - is as much a revolutionary innovation as the virtual stock market. In this more radical view, globalisation is also seen as multidirectional. It acknowledges the powerful influence of global economic forces on local communities, but it also recognises the revival of local cultural identities as communities find different ways to enact their resistance to McDonaldisation. The 'new localism', as it is called, also provides the creative energy for customising and embedding development initiatives that may begin internationally, such as the very successful Healthy Cities movement..$^{15}$ Finally, this wider perspective on globalisation sees it as small-scale and personal: 'in here' as well as 'out there'. Global influences have a profound impact on our identity, our relationships, our values, our family life, our sexuality, and our lifestyle choices.

The second major force that accounts for the changes in society is 'modernisation' or, more accurately, what sociologists call 'late modernity': the phase in social evolution where we have abandoned 'tradition' as conventionally defined, and where science and technology shape and constrain all aspects of our lives. ${ }^{16}$ Late modernity is a phase of rapid change, where new scientific and technological advances are continually making today's ideas and lifestyles obsolete, and where words like 'innovation' and 'growth' are synonymous with success.

The American anthropologist Margaret Mead developed a conceptual model of social evolution, subsequently extended by James Coté, which distinguished three key eras: pre-modern or traditional society; modern (industrial) society; and late modern or post-industrial society (Table 1). ${ }^{17,18}$ Some people since then have used the term 'post-modern' for this last era, but that has so much philosophical baggage attached that I feel it is best avoided.

In pre-modern society, social relations are determined by one's position in the family, and the family's position in wider society. In industrial societies, we define our social relations by our work - by who we are in relation to what Karl Marx called the means of production. But in late modern society, because technology has created all sorts of surpluses that need to be consumed, social relations come to be defined in terms of patterns of consumption. How - and with whom - do we spend our leisure time; what lifestyles do we lead; what do we spend our money on? And social class becomes defined by what patterns of consumption we can afford to indulge in.

These changes in society have driven a profound change in the nature of identity. In pre-modern society, a person's identity was fixed at birth. In industrial society, identity was acquired in childhood, through socialisation and parenting, and while my own generation sure kicked against that process, in the end we turned out pretty much how our parents wanted. But in post-industrial society, change is so

Table 1. Three eras in social evolution (Coté, adapted from Mead)..$^{17,18}$

\begin{tabular}{lccc} 
& Pre-modern & Modern (industrial) & Late modern (post-industrial) \\
\hline Determinant of social relations & $\begin{array}{c}\text { Family } \\
\text { (kinship ties) }\end{array}$ & $\begin{array}{c}\text { Work (relationship to } \\
\text { the 'means of production') }\end{array}$ & $\begin{array}{c}\text { Consumption (leisure, } \\
\text { lifestyle, spending) }\end{array}$ \\
\hline The family & $\begin{array}{c}\text { Rigid roles; children } \\
\text { learn from parents }\end{array}$ & $\begin{array}{c}\text { Expected but negotiable } \\
\text { roles; learn from peers }\end{array}$ & $\begin{array}{c}\text { Parents' experience 'irrelevant'; } \\
\text { parents learn from children }\end{array}$ \\
\hline Social class defined by & Inherited position & Occupation & Access to resources \\
\hline Nature of identity & Fixed at birth & $\begin{array}{c}\text { Developed by socialisation } \\
\text { and parenting }\end{array}$ & $\begin{array}{c}\text { Flexible; responsive to } \\
\text { emerging challenges }\end{array}$ \\
\hline
\end{tabular}


endemic and so rapid that the experience and knowledge offered by our parents is sometimes seen as irrelevant. Children, because they are adaptable and on top of new technologies, have (in some aspects of life) become the experts, and the direction of knowledge transmission may be reversed - with parents either choosing to remain ignorant or seeking to learn from their children. Small wonder that more teenagers seem to go off the rails and nobody seems to know what to do about the 'parenting crisis'.

In his Reith Lectures, ${ }^{14}$ Giddens offered an upbeat solution to this problem: individualisation. By that he meant not self-centredness but the ability to do what is fashionably referred to as 'reinventing oneself'. Society is increasingly fragmented; its values are increasingly eroded; public trust in our institutions is plummeting; change and uncertainty bear down upon us like never before in history - but, according to Giddens, the individual has the agency and the wherewithal to construct a new identity wherever needed, and to move between multiple identities. In late modernity, identity becomes a 'bricolage' of potential selves fashioned to meet the demands of the moment. The sociological study of identity, incidentally, is not without controversy, having been described as inconsistent, under-theorised, and contradictory (being on the one hand fragmented and fluid, and on the other hand the essential 'sameness' that holds the individual psyche together)..$^{19}$ I have a personal research interest in narrative, and a key aspect of that is the role of narrative in the construction and reconstruction of identity in the face of complexity and change..$^{20}$

Individualisation is not merely a psychological coping mechanism. It is also about managing risk. Late modern society offers many hazards, which are to a large extent of our own making, and we must learn to manage and work around them if we are to survive. Sociocultural change, new technologies, and scientific progress all offer exciting opportunities for the individual, but they are also associated with potential dangers. Ulrich Beck, in his important book The Risk Society, defines risk as 'A systematic way of dealing with hazards and insecurities induced and introduced by modernisation itself'. ${ }^{21}$

Those who succeed in managing risk can look forward to affluence, upward social mobility, psychological fulfillment, and a long and healthy life. Those who fail will find themselves at the margins of society, grazing miserably on cheap hamburgers; taking drugs; abusing alcohol; with unwanted pregnancies; or on the giving or receiving end of violence.

It is surely no coincidence that the world suicide map (http://www.who.int/mental_health/prevention/su icide/suicideprevent) shows highest incidence in countries where modernisation has occurred most rapidly and with greatest disruption of traditional cultures and communities: the former USSR and Eastern Europe; China; Japan; and Australia (where suicide rates among Aboriginal people are among the highest in the world).

The individual's successful management of risk is, of course, the cornerstone of preventive care and chronic disease management. And research tells us that managing risk requires, in addition to literacy and numeracy, a very contemporary set of competencies and resources: self efficacy and resilience; access to knowledge and technologies; social and cultural capital; and extensive interpersonal networks. ${ }^{22-24}$ The new localisation, for example, delivered through television, the World Wide Web, and social movements, allows women as far apart as Kazakhstan, Indonesia, Bolivia, and Somalia to discover a common oppression and sense of solidarity, and through this begin to develop the personal resources to improve their lot. ${ }^{25}$

Let us return to patterns of consumption and why they matter. 'Consumerism' in health care is often equated with demanding middle-class patients with unrealistic expectations. But in a sociological sense, consumerism is about how our identity is fashioned by the lifestyle choices we make. ${ }^{26}$ Whether it is drinking Coca-Cola ${ }^{\circledR}$, going to the gym, or meeting our friends in Starbucks ${ }^{\mathrm{T}}$, we do it partly - and perhaps largely - because these patterns of consumption define who we are. The reason we want to hold our child's birthday party in McDonald's 's is because McDonald's defines a happy, family-oriented, generous, and safe sort of birthday. We eat sushi because we are sophisticated and cosmopolitan. And men in transition economies smoke, perhaps, because they hold a perception that it makes them appear rich and sexually attractive to western women.

So in summary, many, though not all, of the changes in health need over the past two generations can be tracked back to the four powerful forces of globalisation, modernisation, individualisation, and consumerism. Together they have shaped a complex, fast-moving, high-technology society in which there is both unprecedented risk and unprecedented opportunity. There are winners and losers - and perfect health (that elusive state of complete physical, psychological, and social wellbeing) is as much about individual identity and management of risk as it is about pathological processes, the new genetics, or designer drugs.

So now to the final theme covered in my lecture: what (if anything) can we salvage from our nostalgic memories of general practice that will help us deliver primary care in 2008? Nostalgia, of course, distorts our perception and creates a golden past that probably never existed. The task is not to set out to 
recreate the entire package that Pickles offered his patients in the days when 'cradle-to-grave care' was on the lips of every social reformer, but to identify and defend aspects of old-fashioned general practice that are core components of 'quality' care today.

Before I try to bring William Pickles into the modernday GP-led health centre, I would like to introduce a report recently published by the inspirational $\mathrm{Dr}$ Shigeru Omi, Regional Director of the World Health Organization Western Pacific, on what he has called 'People-Centred Health Care'. ${ }^{27}$ He seeks a fundamental shift from a disease and technologycentred health system to a human-centred one. To achieve health for all in the 21st century, he argues, individuals, families, and communities must be informed and empowered; health practitioners must be competent and responsive; healthcare organisations efficient and benevolent; and health systems supportive and humanitarian. How will we achieve those high-level goals?

Firstly (and this applies whatever the country, the political system, the demographics, or the particular disease burden), for individuals and communities there must be attention to improving health literacy, developing shared decision-making skills, enhancing self-care potential, building the capacity of the voluntary sector, and public participation in community development. Secondly, in relation to health practitioners, we need to increase their capacity to provide holistic, compassionate care; ensure that every practitioner is committed to quality and safety; develop patient-centredness; and, not least, pay attention to the welfare of the practitioners themselves. Thirdly, in relation to healthcare organisations, we must ensure a physical environment that is fit for purpose; support coordination of care; strengthen multidisciplinary care; and integrate patient self-management with existing protocols and systems of care. Finally, at the health system level, Dr Omi's top priority is the development and strengthening of primary health care. Below that come system-level incentives to induce positive provider behaviour; developing the evidence base; optimising the use of technology; and attention to standards and accountability. ${ }^{27}$

This is a grand vision, and because of the sheer complexity and pervasiveness of the problems discussed above, we cannot achieve it through conventional institutions, hierarchies, or intellectual empires. We cannot do it wholly within primary care, or even wholly within health care. We need crossdisciplinary, cross-sector approaches that are characterised by flexibility, emergence, and diversity.

Two such approaches are the Institute for Global Health at University College London (http://www.ucl.ac.uk/global-health/) and my own work with Primary Care Connect, comprising current and past students on our online Masters degree in International Primary Health Care (http://www.londonexternal.ac.uk/iphc/connect/issu e1_08.pdf). The latter is what the technology sociologists call a 'virtual community of practice', a place where people share and develop ideas and make the link between global vision and local action.

I hope that the evidence presented in this paper shows that I am not opposed to innovation or new technologies in addressing the challenges of primary care in 2008. But I now want to return to my question: what can we salvage from the era of William Pickles that will help us do this effectively? Yes, we need to frame some problems in new ways; for example, considering the link between modernity, identity, and the inability to manage personal risk effectively. Yes, we doctors need to move over and make room for other professional groups and the voluntary sector. Some award-winning general practices are now owned and managed entirely by nurses, and some people with mental health problems, drug dependency, or dementia are managed very effectively by unqualified volunteers working in church halls or mosques. But despite these important changes, and very much linked with them, I think there are three core characteristics of old-fashioned general practice that we need to keep close hold of, because they are even more critical for dealing with the diseases of modernity than they were for dealing with last century's problems.

The first is the unique link that is built over time through continuity of care between the primary care practitioner and his or her local community. ${ }^{28-30}$ However clever you are, whatever your formal qualifications and training, there is simply no substitute for the internalised, embodied knowledge that comes from years of listening to stories, building relationships, touching the flesh, responding to real or perceived crises, and witnessing the suffering, healing, coping, and dying of ordinary folk. ${ }^{31}$ That is not to say that this tacit, hard-won knowledge about your patient population and their health needs cannot be supplemented by more formal sorts of data, such as the rapid community appraisal technique developed by Scott Murray and his team in Edinburgh, ${ }^{32}$ or the automated analysis of electronic data to inform practice-based commissioning, with tools like Dr Foster Intelligence (http://www.drfosterintelligence.co.uk/managementl nformation/PBC/). But as anyone who has taken over a GP practice from someone else will tell you, it takes around 6 years to really get to know your practice population.

The second thing we must fight to retain from the era of William Pickles is the high value placed on 
humanism. ${ }^{31,33,34}$ We admire Pickles not just for what he did but for the kind of person he was. The oldfashioned family doctor usually had no illusions about the weaknesses and idiosyncracies of his or her patients - there are sections in Epidemiology in Country Practice that would not pass a test of political correctness today - but it was part of the family doctor's job to take folk on, literally warts and all; to care for them in a professional, non-judgemental and wholly altruistic way; and to advocate passionately for the sick, the vulnerable, and the inarticulate. Many readers of this lecture, I am sure, are examiners for undergraduate or postgraduate medical degrees. They may have experienced, as I certainly have, a feeling of dissatisfaction when required to use an objective, structured clinical examination (OSCE) to assess whether a student is capable of engaging and empathising with a patient, breaking bad news, or dealing with conflict. Did the student make adequate eye contact (yes/no)? Did they remain silent for the required number of seconds? Did they say goodbye and smile when leaving the room? Since we cannot climb inside our students' heads or hearts, we can only ever assess performance, so the OSCE is undoubtedly here to stay. ${ }^{35}$ But as teachers and tutors, we all know that if the assessment-oriented student is ever going to make a patient-oriented doctor, we must inspire and motivate them in the same way the great clinicians of our youth inspired us - by our own human example.

Thirdly, and I say this even though I am a great fan of large-scale, centrally organised collaborative research, we must celebrate and defend the role of the individual front-line clinician in defining and taking forward the research agenda in primary care. William Pickles was a full-time GP. He had no protected time for research, nor did he have a Masters degree or a PhD. He had been introduced to some relatively simple research techniques in his formative years by James McKenzie; and he immediately saw how they might be applied in his practice, to the direct benefit of his own patients, as well as contributing to the wider knowledge base. ${ }^{1}$ It is an indictment of our increasingly fragmented, targetdriven primary care system that research tends to sit in one corner of a triangle, education and training in another, and front-line clinical practice in a third. Even GP academics like myself, ostensibly to preserve sanity, divide their working week into 'research days', 'teaching days', and 'clinical days'. Yet the impact zone for high-quality primary health care lies, as in Pickles' day, at the interface between these three spheres of activity. Only when clinical practice and teaching are informed by research evidence and where research is inspired and energised by real day-to-day clinical questions, will primary care have maximum impact on people's health and wellbeing.
It is not as easy as it used to be. The nature of much research has moved on from Pickles' day. A smalltown epidemiologist could not map the spread of SARS, HIV, or (God forbid) pandemic flu across the world using the same instruments and analytic techniques that Pickles used to map the spread of chickenpox up and down the winding roads of Wensleydale. You need the new technologies and international collaborations I alluded to earlier. But this does not mean that we have already answered all the research questions that could possibly be answered by a jobbing GP in his or her humble surgery.

To use one example from my own PhD students, Gary Parkes is a full-time GP in Hoddesden who took our distance learning Masters in International Primary Health Care and then applied for a Health Foundation grant to buy himself out 1 day a week to explore ways of improving the success of smoking cessation strategies. Unlike a researcher who parachutes into someone else's patch, Gary knew his patients and the local turf. Like William Pickles before him, he worked hard to train and supervise his staff in simple but meticulous data collection methods. He understood the importance of completeness of follow-up, and applied local knowledge to track down defaulters, resulting in an $89 \%$ follow-up of nearly 600 patients. Gary's intervention, born of a clever idea that arose in practice, doubled the success of smoking cessation efforts compared to a control group, and was sustained at 12 months. ${ }^{36}$

Gary, and others like him, represent 'entrepreneur' researchers in primary health care: ${ }^{37}$ people whose interest in research arose directly out of their clinical commitment and curiosity, and whose academic work has been driven by their passion to improve primary care services for their patients. This is what Andrew Van de Ven has called 'engaged scholarship', ${ }^{38}$ and those of us who lay claim to a leadership role in academia should make it our first priority to find, nurture, and support students like these.

So to conclude, let me return to the four themes I introduced at the beginning of this paper. William Pickles inspired us as a dedicated family doctor whose clinical curiosity drove a programme of worldclass research. Alma-Ata was primary health care's first global mission statement. Its words stir our hearts as strongly today as they did 30 years ago. Society has changed immeasurably, and both patients and communities have shown that they must adapt to survive in an uncertain, risk-laden, hightechnology world. Primary care must in turn adapt to accommodate these changes in society. While both the structure of primary care and many aspects of its operation should and will change with the times, three things - continuity of care, humanism, and practicebased research - are needed more than ever. 


\section{Competing interests}

The author has stated that there are none

\section{Discuss this article}

Contribute and read comments about this article on the Discussion Forum: http://www.rcgp.org.uk/bjgp-discuss

\section{REFERENCES}

1. Pickles W. Epidemiology in country practice. Bristol: John Wright, 1938

2. Anonymous. Declaration of Alma Ata. Alma Ata, USSR: International Conference on Primary Health Care, 6-12 September, 1978. http://www.who.int/hpr/NPH/docs/ declaration_almaata.pdf (accessed 18 Sep 2008).

3. Balint M. The doctor, his patient and the illness. London: Routledge, 1956.

4. Black D. Inequalities in health: report of a working group. London: Department of Health and Social Security, 1980.

5. Hart JT, Hart M. Present state and future needs of primary care in Kazakhstan and Kirghistan: report of a visit March 18th - April 8th 1995. London: Royal Free Medical School Department of Primary Health Care, 1995.

6. Anonymous. World economic factbook 2008. London: Euromonitor International, 2007

7. Facchini F, Fiori G. The modernizing Kazakhstan: a review of biomedical data. J Physiol Anthropol Appl Human Sci 2001; 20(2): 95-103.

8. Facchini F, Fiori G, Bedogni G, et al. Prevalence of overweight and cardiovascular risk factors in rural and urban children from Central Asia: the Kazakhstan health and nutrition examination survey. Am J Hum Biol 2007; 19(6): 809-820.

9. Gilmore A, Pomerleau J, McKee M, et al. Prevalence of smoking in 8 countries of the former Soviet Union: results from the living conditions, lifestyles and health study. Am J Public Health 2004; 94(12): 2177-2187.

10. Pomerleau J, McKee M, Rose R, et al. Hazardous alcohol drinking in the former Soviet Union: a cross-sectional study of eight countries. Alcohol Alcohol 2008; 43(3): 351-359.

11. Aceijas C, Friedman SR, Cooper HL, et al. Estimates of injecting drug users at the national and local level in developing and transitional countries, and gender and age distribution. Sex Transm Infect 2006; 82(Suppl 3): iii10-iiil7.

12. Agadjanian V. Is 'abortion culture' fading in the former Soviet Union? Views about abortion and contraception in Kazakhstan. Stud Fam Plann 2002; 33(3): 237-248.

13. Snajdr E. Ethnicizing the subject: domestic violence and the politics of primordialism in Kazakhstan. J R Anthropol Inst 2007; 13(3): 603-620.

14. Giddens A. Reith Lectures 1999. Runaway world. British Broadcasting Corporation. http://news.bbc.co.uk/hi/ english/static/events/reith_99/ (accessed 17 Sep 2008).

15. Kickbusch I. Global + local $=$ glocal public health. $J$ Epidemio Community Health 1999; 53(8): 451-452.

16. Appadurai A. Modernity at large: cultural dimensions of globalization. Minneapolis: University of Minnesota Press, 1996.

17. Mead M. Culture and commitment. A study of the generation gap. Garden City: Doubleday, 1970.

18. Coté JE. Sociological perspectives on identity formation: the cultureidentity link and identity capital. J Adolesc 1996; 19(5): 417-428.

19. Bendle MF. The crisis of 'identity' in high modernity. Br J Sociol 2002 53(1): $1-18$

20. Greenhalgh T. 'What seems to be the trouble?': Stories in illness and health care. Oxford: Radcliffe, 2006.

21. Beck U. Risk society: towards a new modernity. London: Sage, 1992.

22. Werner EE. Journeys from childhood to midlife: risk, resilience, and recovery. Pediatrics 2004; 114(2): 492.

23. Catania JA, Kegeles SM, Coates TJ. Towards an understanding of risk behavior: an AIDS Risk Reduction Model (ARRM). Health Educ Behav 1990; 17(1): 53-72.

24. Seeman TE, Crimmins E. Social environment effects on health and aging: integrating epidemiologic and demographic approaches and perspectives. Ann N Y Acad Sci 2001; 954: 88-117.

25. Hamm S. Information communications technologies and violence against women. Development 2001; 44(3): 36-41.

26. Lupton D. Consumerism, commodity culture and health promotion Health Promot Int 1994; 9(2): 111-118.

27. Omi S. People at the center of health care: harmonizing mind and body, people and systems. Geneva: World Health Organization, 2007. http://www.wpro.who.int/publications/PUB_139789290613169.htm

28. Cabana MD, Jee SH. Does continuity of care improve patient outcomes? J Fam Pract 2004; 53(12): 974-980.

29. Sans-Corrales M, Pujol-Ribera E, Gene-Badia J, et al. Family medicine attributes related to satisfaction, health and costs. Fam Pract 2006; 23(3): 308-316.

30. Mead N, Bower P, Roland M. Factors associated with enablement in general practice: cross-sectional study using routinely-collected data. $\mathrm{Br}$ J Gen Pract 2008; 58(550): 346-352.

31. Heath I. The mystery of general practice. London: Nuffield Provincial Hospital Trust, 1997.

32. Murray SA, Tapson J, Turnbull L, et al. Listening to local voices: adapting rapid appraisal to assess health and social needs in general practice. BMJ 1994; 308(6930): 698-700.

33. Biderman A. Family medicine as a frame for humanized medicine in education and clinical practice. Public Health Rev 2003; 31(1): 23-26.

34. Rourke JT. 'An honour and a privilege'. Can Fam Physician 2004; 50: 983.

35. Rushforth HE. Objective structured clinical examination (OSCE): review of literature and implications for nursing education. Nurse Educ Today 2007; 27(5): 481-490.

36. Parkes G, Greenhalgh T, Griffin M, Dent R. Effect on smoking quit rate of telling patients their lung age: the Step2quit randomised controlled trial. BMJ 2008; 336(7644): 598-600.

37. Macfarlane F, Shaw S, Greenhalgh T, Carter YH. General practices as emergent research organizations: a qualitative study into organizationa development. Fam Pract 2005; 22(3): 298-304.

38. Van de Ven AMS. Engaged scholarship: a guide for organizational and social research. Oxford: Oxford University Press, 2007. 